\title{
Preparation and Property Analysis of Phase Change Concrete PEG/SiO2-CPCM
}

\author{
Juan Yang ${ }^{1,2 *}$, Jianting Zhou ${ }^{1}$, Zhixin Nie $^{1}$, Lu Liu ${ }^{1}$ \\ ${ }^{1}$ School of Civil Engineering, Chongqing Jiaotong University, Chongqing 400074, China \\ ${ }^{2}$ China Merchants Chongqing Transportation Research and Design Institute Co., Ltd, Chongqing 400070, China
}

Corresponding Author Email: 460748723@qq.com

https://doi.org/10.18280/rcma.290104

Received: 25 November 2018

Accepted: 3 February 2019

\author{
Keywords: \\ polyethylene glycol (PEG), silica sol, \\ phase change concrete, compressive \\ strength, thermal conductivity
}

\begin{abstract}
With polyethylene glycol (PEG) as the phase change material (PCM), and silica sol as inorganic porous carrier, this paper prepares the polyethylene glycol/silica sol composite phase change material ( $\left.\mathrm{PEG} / \mathrm{SiO}_{2}-\mathrm{CPCM}\right)$ using sol-gel method, and adds $\mathrm{PEG} / \mathrm{SiO}_{2}-\mathrm{CPCM}$ into concrete to prepare phase change concrete according to the absolute volume method. Next, this paper uses scanning electron microscopy (SEM) and differential scanning calorimetry (DSC) to characterize the microstructure, compatibility, stability and energy storage of $\mathrm{PEG} / \mathrm{SiO}_{2}-\mathrm{CPCM}$, and tests the compressive strength and thermal conductivity of the phase-change concrete. The results show that PEG-2000 had a good compatibility with $\mathrm{SiO}_{2}$; the mass fraction of PEG in the CPCM should be controlled within $90 \%$; after 200 thermal cycles, the mass loss is less than $1 \%$. The $\mathrm{PEG} / \mathrm{SiO}_{2}-\mathrm{CPCM}$ starts to undergo phase change at the temperature of $42.4{ }^{\circ} \mathrm{C}$; the strength of the phase-change concrete with a $5 \%$ PEG content dropped by about $4.96 \%$; under the premise of ensuring good working performance, the addition of the $\mathrm{PEG} / \mathrm{SiO}_{2}-\mathrm{CPCM}$ can greatly enhance the thermal conductivity of the concrete.
\end{abstract}

\section{INTRODUCTION}

Concrete is a kind of material with poor thermal conductivity. Under the influence of sunlight, there is often a large temperature difference between the inside and the outside of the box section, which produces significant temperature difference stress and results in a large temperature difference tensile stress. As the tensile strength of the concrete structure is only 2-3 Mpa, the concrete box structure often has surface cracks due to the large temperature difference between the inside and outside of the section. The existing research results show that when the temperature difference between the inner and outer surfaces of the concrete box is greater than $10{ }^{\circ} \mathrm{C}$, the temperature stress may be greater than $2.5 \mathrm{MPa}$. As long as measures are taken to reduce the temperature difference between the inner and outer surfaces to a certain extent, the occurrence of concrete cracks could be avoided [1, 2].

Phase Change Materials (PCMs), also known as latent thermal energy storage materials (LTES), utilize the heat absorbed or released during the phase change process to keep the temperature of the material itself relatively stable, and it has the functions of heat storage and temperature regulation [3]. Therefore, in the fields of building energy conservation, engineering structure cooling, road maintenance, etc., people add PCMs to concrete by direct mixing or encapsulating in the hopes of obtaining phase-change concrete with "selftemperature regulation effect" [4-7]. There are various PCMs, but those suitable for construction engineering are often solidliquid PCMs such as paraffin and aliphatic acids. Such PCMs generally have the advantages of suitable phase change temperature, high phase change enthalpy, low price and no supercooling [8-10].
PEG has received wide attention due to its advantages of wide phase change temperature range, high latent heat of phase change, good thermal stability, no phase separation, low degree of supercooling, safe and non-toxic, no volatility, low corrosivity, and stable chemical properties, etc. However, in terms of phase-change patterns, PEG is a kind of organic solidliquid phase change heat storage material, that is, during the phase-change process, flowing liquid will be generated and it's easy to leak when in use, which has greatly limited its practical applications [11-13]. Silica sol is an ideal inorganic porous carrier. It has a rich three-dimensional network porous structure after gelation, and large pore volume and specific surface area. It can firmly adsorb the phase change heat storage materials into its microporous structure, and its action with the phase change heat storage material is only a physical interaction, which does not damage the heat storage performance of the phase change heat storage material; moreover, it has good shaping effect, wide sources, low price, safety and non-toxicity. Therefore, this study adopts silica sol to mix with PEG-2000 to prepare the $\mathrm{PEG} / \mathrm{SiO}_{2} \mathrm{CPCM}$.

This paper prepares $\mathrm{PEG} / \mathrm{SiO}_{2}-\mathrm{CPCM}$ using sol-gel method, and tests its microstructure, thermal properties, and cyclic phase change stability, at last, it adds PEG of different proportions to the CPCM to study its influence on the strength and thermal conductivity of the concrete.

\section{EXPERIMENT}

\subsection{Raw materials}

PEG is a commonly used polyether phase change heat storage material, its molecular structure is consisted of long- 
chain polymers with hydroxyl groups at both ends, and it has good hydrophilicity. According to different polymerization degrees, a series of polymers with average molecular weights ranging from 200 to 20,000 can be formed. Through experiments it's found that PEG with a molecular weight of 2000 is most suitable for engineering structure related applications [16]. PEG used in this experiment is produced by Tianjin Guangfu Fine Chemical Research Institute and is provided by Shanghai Macklin Biochemical Co., Ltd, analytically pure, its phase change start temperature is about $38.2{ }^{\circ} \mathrm{C}$, peak temperature is $52.2{ }^{\circ} \mathrm{C}$, end temperature is $72.2{ }^{\circ} \mathrm{C}$, and the phase change enthalpy reaches $185.8 \mathrm{~J} / \mathrm{g}$.
Silica sol: industrial grade, produced by Zhejiang Yuda Chemical Co., Ltd., mass content $30 \%$, particle size $11.7 \mathrm{~nm}$, $\mathrm{pH}$ value 9.9 , density $1.198 \mathrm{~g} / \mathrm{cm}^{3}$ at $20{ }^{\circ} \mathrm{C}$.

\subsection{Preparation of $\mathrm{PEG} / \mathrm{SiO}_{2}$ composite shape-stabilized phase change material}

This paper adopted the sol-gel method. At room temperature, PEG of a certain mass ratio was added into the silica sol solution, the mass ratio of the PEG and the silica sol is shown as Table 1.

Table 1. Mass ratio of PEG and silica sol

\begin{tabular}{|c|c|c|c|c|c|c|c|c|}
\hline Composite shape-stabilized phase change material & $1 \#$ & $2 \#$ & $3 \#$ & $4 \#$ & $5 \#$ & $6 \#$ & $7 \#$ & $8 \#$ \\
\hline Percentage (\%) & 0 & 30 & 40 & 50 & 60 & 70 & 80 & 90 \\
\hline PEG Mass (g) & 0 & 12.9 & 20 & 30 & 45 & 70 & 120 & 270 \\
\hline Silica Sol Mass (g) & 100 & 100 & 100 & 100 & 100 & 100 & 100 & 100 \\
\hline
\end{tabular}

The mixture of PEG and silica sol was thoroughly mixed with a glass rod or electric stirring paddle until the PEG flakes or powders completely disappeared, so that the PEG was uniformly dispersed in the silica sol; then calcium chloride solution of a certain concentration was added into the mixture and stirred constantly until the mixture was completely gelled. The preparation process is shown in Figure 1.

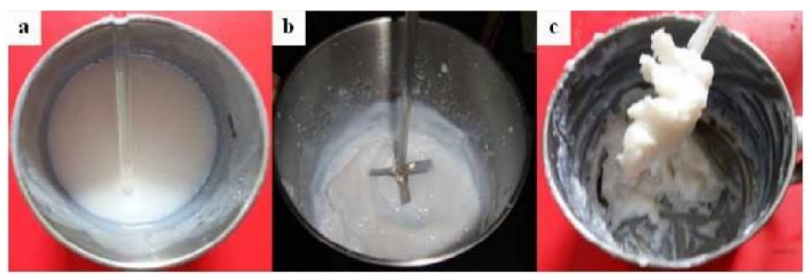

Figure 1. Preparation flow of $\mathrm{PEG} / \mathrm{SiO}_{2}$ composite shapestabilized phase change material

In the preparation process of $\mathrm{PEG} / \mathrm{SiO}_{2}$ composite shapestabilized phase change material, when the mass fraction of PEG reached $90 \%$ (8\# mass ratio), the $\mathrm{PEG} / \mathrm{SiO}_{2}$ composite shape-stabilized phase change material was dried at room temperature and then formed pie-shaped lumps and the surface was sticky; When heated, the material presented a semi-flow state, and there were some liquid PEG exuded from edges and corners, indicating that the mass fraction of PEG was too high and the microporous capacity of the $\mathrm{SiO}_{2}$ gel had reached saturation, the excess PEG molecules formed a coating on the surface of the $\mathrm{SiO}_{2}$ gel, since there's no binding force, the PEG molecules were heated and underwent solid-liquid phase change, producing flowing liquid phase, which affected the shaping effect. In the two coagulation methods, the phenomenon occurred in the $8 \#$ mass ratio, while for $1 \# \sim 7 \#$ mass ratios, PEG liquid exudation did not occur. Therefore, it can be preliminarily judged that the mass fraction of PEG in $\mathrm{PEG} / \mathrm{SiO}_{2}$ composite shape-stabilized phase change material should be lower than $90 \%$.

\subsection{Test and characterization methods}

By comparing and observing the appearance of $\mathrm{PEG} / \mathrm{SiO}_{2}-$ CPCM of different ratios and judging whether there're lumps on the surface, the saturated adsorption rate could be determined, and then SEM (model: KYKY-2800B, produced by Gold APP Instrument Corporation China) was used to analyze its surface morphology and microstructure and study the adsorption of PEG-2000 by $\mathrm{SiO}_{2}$.

The structural characteristics of $\mathrm{PEG} / \mathrm{SiO}_{2}-\mathrm{CPCM}$ were characterized by an infrared spectrometer (model: Spectrum 100, produced by PerkinElmer U.S.), the compatibility of PEG-2000 and $\mathrm{SiO}_{2}$ was analyzed. The sample preparation method was $\mathrm{KBr}$ pellets method, and the scanning frequency was 3 times.

The phase change temperature and latent heat of phase change of PEG-2000 and PEG/SiO 2 -CPCM were tested by a thermal gravimetric analyzer (model: STA449C, produced by NETZSCH, Germany), the scanning temperature of the instrument was $20{ }^{\circ} \mathrm{C} \sim 130{ }^{\circ} \mathrm{C}$, and the temperature heating/cooling rate was $2{ }^{\circ} \mathrm{C} / \mathrm{min}$. Both the sweep gas and protective gas were high purity nitrogen with a gas flow rate of $20 \mathrm{~mL} / \mathrm{min}$. First, temperature rose from $20^{\circ} \mathrm{C}$ to $130{ }^{\circ} \mathrm{C}$, the water was evaporated and the influence of historical temperature was eliminated, then the temperature dropped from $130{ }^{\circ} \mathrm{C}$ to $20^{\circ} \mathrm{C}$, the temperature was kept for $2 \mathrm{~min}$, and then the temperature rose from $20^{\circ} \mathrm{C}$ to $130{ }^{\circ} \mathrm{C}$ again.

A certain amount of $\mathrm{PEG} / \mathrm{SiO}_{2}-\mathrm{CPCM}$ particles were naturally deposited on the filter paper, then placed in a vacuum drying oven to undergo $20{ }^{\circ} \mathrm{C}-80{ }^{\circ} \mathrm{C}$ phase change thermal cycle for 10, 20, 50, 100, and 200 times, and the mass loss situation was recorded.

For the compressive strength test, the test pieces were cubic blocks with a size of $100 \times 100 \times 100 \mathrm{~mm}, 6$ blocks in each group, cured for $3 \mathrm{~d}, 7 \mathrm{~d}$ and $28 \mathrm{~d}$ respectively, and then subject to the test using WE-1000 hydraulic universal testing machine according to the requirements of GB/T 50081-2002 Standard for Test Method of Mechanical Properties on Ordinary Concrete, the compressive strength test loading rate was $5 \mathrm{kN} / \mathrm{s}$, the indoor temperature was $25^{\circ} \mathrm{C}$, and the loading rate was uniform and continuous.

The thermal conductivity of concrete with different mixing ratios was tested by a smart plate thermal conductivity tester (model: IMDRY600-II). The size of the test pieces was $600 \times 600 \times 50 \mathrm{~mm}$, and the number of the test pieces was the same as the ratio of the cubic blocks. Before the test, the test pieces were put in the oven for $48 \mathrm{~h}$, the test time was $6 \mathrm{~h}$, and the sampling interval was $10 \mathrm{~min}$. The two states of normal temperature and high temperature phase change were tested respectively. Under the normal temperature state, the cold 
plate temperature was $15{ }^{\circ} \mathrm{C}$, the hot plate temperature was $35^{\circ} \mathrm{C}$, under the high temperature phase change state, the cold plate temperature was $40{ }^{\circ} \mathrm{C}$, and the hot plate temperature was $60{ }^{\circ} \mathrm{C}$.

\subsection{Design of phase change concrete mixing ratios}

The test pieces were cubic blocks with a size of $100 \times 100 \times 100 \mathrm{~mm}$, the concrete volume for the on-site material fabrication was $0.01 \mathrm{~m}^{3}$. The particle size of larger pebbles was $10 \sim 20 \mathrm{~mm}$, and the particle size of smaller pebbles was $5 \sim 10 \mathrm{~mm}$, the mixing ratio was $6: 4$. All pebbles were sieved to reduce the content of mineral powder, and the apparent density of the pebbles was $2734.1 \mathrm{~kg} / \mathrm{m}^{3}$; the sand was medium sand with an apparent density of $2635 \mathrm{~kg} / \mathrm{m}^{3}$ and a modulus coefficient of 2.83 , the water content is negligible; For cement, the ordinary Portland cement $42.5 \mathrm{R}$ (brand: Xiaonanhai) was adopted; the water reducing agent was highefficient polycarboxylate water reducer with a water reduction rate of $20 \%-25 \%$, the recommended content was $0.8 \% \sim 1.2 \%$; after the dried gel was ground and sieved, powders of the composite shape-stabilized phase change material with a particle size less than $0.6 \mathrm{~mm}$ can be obtained, namely the $\mathrm{PEG} / \mathrm{SiO}_{2}-\mathrm{CPCM}$, and its apparent density could reach 1.39 $\mathrm{g} / \mathrm{cm}^{3}$.

Table 2. Mixing ratio of standard concrete

\begin{tabular}{|c|c|c|c|c|c|c|}
\hline Water cement ratio & $\begin{array}{c}\text { Water } \\
/ \mathrm{kg}\end{array}$ & $\begin{array}{c}\text { Cement } \\
/ \mathrm{kg}\end{array}$ & $\begin{array}{c}\text { Medium sand } \\
/ \mathrm{kg}\end{array}$ & $\begin{array}{c}\text { Pebbles } \\
/ \mathrm{kg}\end{array}$ & $\begin{array}{c}\text { Fly ash } \\
/ \mathrm{kg}\end{array}$ & $\begin{array}{c}\text { Water reducing agent } \\
/ \mathrm{kg}\end{array}$ \\
\hline 0.35 & 148 & 420 & 720 & 1080 & 100 & 6.24 \\
\hline
\end{tabular}

Table 3. Mixing ratio of phase change concrete

\begin{tabular}{|c|c|c|c|c|c|c|c|}
\hline No & Water & Cement & Medium sand & Pebbles & Fly ash & Water reducing agent & PCM volume ratio \\
\hline P-0 & 148 & 420 & 720 & 1080 & 100 & 6.24 & $0 \%$ \\
\hline PEG-V5 & 148 & 420 & 720 & 1080 & 100 & 6.24 & $5 \%$ \\
\hline PEG-V10 & 148 & 420 & 720 & 1080 & 100 & 6.24 & $10 \%$ \\
\hline PEG-V10 & 148 & 420 & 720 & 1080 & 100 & 6.24 & $15 \%$ \\
\hline
\end{tabular}

The mixing ratio of phase change concrete adopted the absolute volume method, and the phase change aggregates were directly added to the mixture according to the volume fraction ratio. A total of 4 groups of comparative experiment were designed for common concrete and $\mathrm{PEG} / \mathrm{SiO}_{2}-\mathrm{CPCM}$ phase change concrete with a volume fraction of $5 \%$ 15\%, the mixing ratio of the phase-change concrete is shown in Table 3, the preparation process of the concrete is shown in Figure 2.

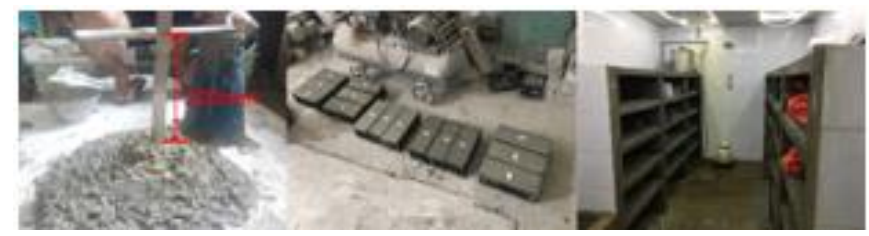

Figure 2. Preparation of concrete test pieces

\section{RESULTS AND DISCUSSION}

\section{1 $\mathrm{PEG} / \mathrm{SiO}_{2}$ adsorption rate and $\mathrm{SEM}$ analysis}

Figure 2 shows SEM graphs of PEG-2000 and PEG/SiO ${ }_{2}$ CPCM. It can be clearly observed that the $\mathrm{SiO}_{2}$ gel has a rich three-dimensional network porous structure, with large specific surface area and strong adsorption capacity; the PEG molecules present continuous and uniform sheet-shaped structures and can be embedded into the three-dimensional network structure by sol-gel interaction. From the right graph we can see that, the PEG/SiO ${ }_{2}$ still maintains the threedimensional network structure, a large number of voids have been filled by PEG-2000 molecules, and the surface gradually becomes smooth, but no lumps or agglomerated PEG-2000 molecules were exposed or existed. Therefore, the PEG/SiO ${ }_{2}-$ CPCM prepared by the sol-gel method can ensure a high adsorption rate and good encapsulation effect.
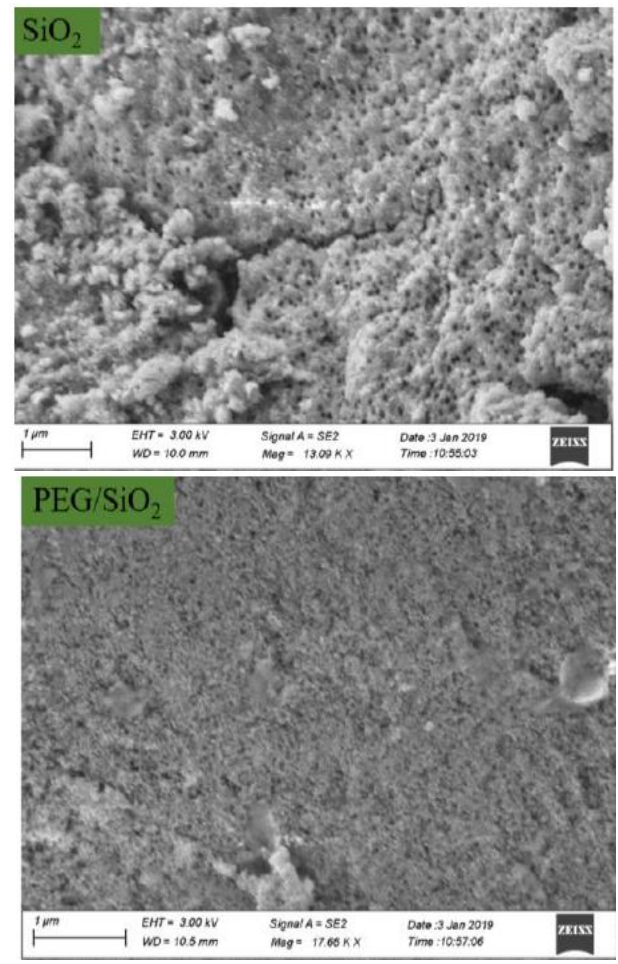

Figure 3. SEM graphs of $\mathrm{SiO}_{2}$ and $\mathrm{PEG} / \mathrm{SiO}_{2}$

\subsection{Compatibility analysis}

Figure 4 shows infrared spectrum graphs of PEG-2000, $\mathrm{SiO}_{2}$ and $\mathrm{PEG} / \mathrm{SiO}_{2}-\mathrm{CPCM}$. It can be seen from Figure 4 that $3343.05 \mathrm{~cm}^{-1}$ is the $-\mathrm{OH}$ antisymmetric stretching vibration peak, which is slightly red shifted compared with pure PEG2000 , this is due to the formation of hydrogen bonds between the $\mathrm{C}-\mathrm{OH}$ of PEG and the $\mathrm{Si}-\mathrm{OH}$ of the $\mathrm{SiO}_{2}$ gel; The peaks at 
$2888 \mathrm{~cm}^{-1}$ and $1468 \mathrm{~cm}^{-1}$ were $\mathrm{C}-\mathrm{H}$ stretching vibration absorption peak and $\mathrm{C}-\mathrm{H}$ bending vibration absorption peak, respectively; the peak at $1344 \mathrm{~cm}^{-1}$ was $-\mathrm{OH}$ in-plane bending vibration absorption peak; and the absorption peaks at $1114 \mathrm{~cm}^{-1}$ and $962 \mathrm{~cm}^{-1}$ were $\mathrm{C}-\mathrm{O}$ antisymmetric stretching vibration peak and $\mathrm{C}-\mathrm{O}$ symmetric stretching vibration peak, respectively; the absorption peak at $842 \mathrm{~cm}^{-1}$ is the $-\mathrm{CH}_{2}$ bending vibration peak, all above mentioned peaks are characteristic absorption peaks of PEG molecules. The crab foot-shaped absorption peak at $800 \sim 1500 \mathrm{~cm}^{-1}$ is the C-O-C bending vibration peak, because the $\mathrm{O}$ in the $\mathrm{C}-\mathrm{O}-\mathrm{C}$ forms a hydrogen bond with the $-\mathrm{OH}$ on the inner surface of the $\mathrm{SiO}_{2}$ gel, so compared with the corresponding peak positions of PEG, a red shift has occurred and the peak intensity is also slightly weakened. Comparing the infrared spectrum graphs of PEG-2000, $\mathrm{SiO}_{2}$ and PEG/SiO $2-\mathrm{CPCM}$, we can see that for the three materials, no obvious new characteristic peak has appeared, and no obvious characteristic peak has disappeared, therefore, the interaction between PEG-2000 and $\mathrm{SiO}_{2}$ is pure physical adsorption, no chemical reaction occurred during the contact of the two, and the compatibility was good.

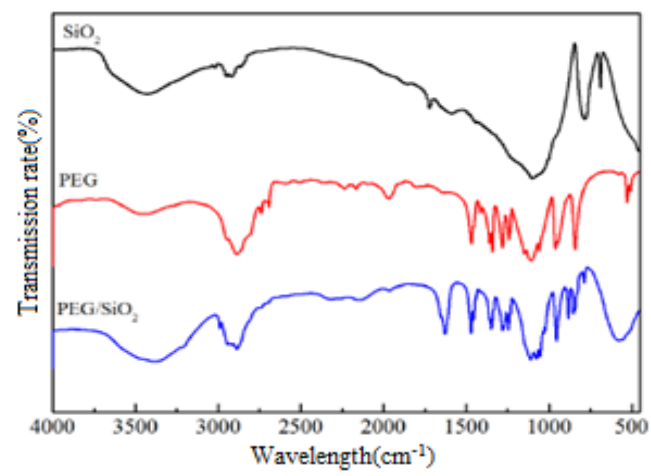

Figure 4. Infrared spectrum graphs of $\mathrm{PEG}, \mathrm{SiO}_{2}$ and $\mathrm{PEG} / \mathrm{SiO}_{2}-\mathrm{CPCM}$

\subsection{DSC analysis}

Figure 5 shows the DSC curves of PEG-2000 and $\mathrm{PEG} / \mathrm{SiO}_{2}-\mathrm{CPCM}$. The results show that, in the heating process, the phase change start temperature and peak temperature of $\mathrm{PEG} / \mathrm{SiO}_{2}-\mathrm{CPCM}$ are about $2{ }^{\circ} \mathrm{C}$ higher than
PEG-2000, their melting intervals are basically the same; the latent heat of phase change of $\mathrm{PEG} / \mathrm{SiO}_{2}-\mathrm{CPCM}$ is significantly lower than that of pure PEG-2000; in the cooling process, the phase change characteristics of PEG-2000 and $\mathrm{PEG} / \mathrm{SiO}_{2}-\mathrm{CPCM}$ are basically the same.

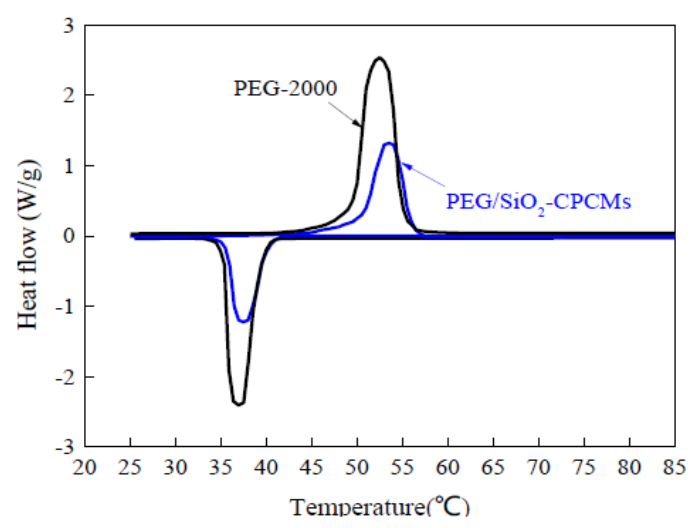

Figure 5. DSC curves of $\mathrm{PEG}$ and $\mathrm{PEG} / \mathrm{SiO}_{2}-\mathrm{CPCM}$

Since the combination of PEG-2000 and $\mathrm{SiO}_{2}$ is purely physical, the phase change enthalpy of $\mathrm{PEG} / \mathrm{SiO}_{2}-\mathrm{CPCM}$ is theoretically linear with the mass fraction of PEG-2000, their relationship can be expressed by Formula (1):

$\Delta H_{\mathrm{t}}=\omega_{P E G} \cdot \Delta H_{\mathrm{PEG}}$

where $\Delta H_{\mathrm{t}}$ is the theoretical enthalpy, $\omega_{P E G}$ is the mass fraction of PEG, $\Delta H_{\mathrm{PEG}}$ is the measured enthalpy.

Table 4 lists the thermal parameters of PEG-2000 and $\mathrm{PEG} / \mathrm{SiO}_{2}-\mathrm{CPCM}$. Using Formula (1), it can be calculated that, in the heating process, the theoretical enthalpy of $\mathrm{PEG} / \mathrm{SiO}_{2}$ CPCM is about $121.03 \mathrm{~J} / \mathrm{g}$, the measured enthalpy is $82.1 \mathrm{~J} / \mathrm{g}$, and the phase change enthalpy is reduced by $38.93 \mathrm{~J} / \mathrm{g}$. Through analysis, it is believed that the coexistence of $\mathrm{SiO}_{2}$ gel and Na+ as an impurity with PEG-2000 will hinder the crystallization performance of PEG-2000. In the gel structure, the ends of PEG-2000 molecules were confined, which has further limited the free condensation and crystallization of PEG-2000, thereby greatly reduces its phase change heat storage capacity [17].

Table 4. Thermal parameters of PEG and PEG/SiO ${ }_{2}-\mathrm{CPCM}$

\begin{tabular}{|c|c|c|c|c|c|c|c|c|c|}
\hline \multirow{2}{*}{ No. } & \multirow{2}{*}{ PEG content } & \multicolumn{4}{|c|}{ Heating process } & \multicolumn{4}{c|}{ Cooling process } \\
\cline { 3 - 11 } & & $T_{\text {on }}\left({ }^{\circ} \mathrm{C}\right)$ & $T_{p}\left({ }^{\circ} \mathrm{C}\right)$ & $T_{\text {end }}\left({ }^{\circ} \mathrm{C}\right)$ & $\Delta H_{m}(\mathrm{~J} / \mathrm{g})$ & $T_{\text {on }}\left({ }^{\circ} \mathrm{C}\right)$ & $T_{p}\left({ }^{\circ} \mathrm{C}\right)$ & $T_{\text {end }}\left({ }^{\circ} \mathrm{C}\right)$ & $\Delta H_{c}(\mathrm{~J} / \mathrm{g})$ \\
\hline PEG-2000 & $100 \%$ & 40.4 & 52.2 & 61.5 & 172.9 & 40.0 & 37.3 & 26.8 & 173.3 \\
\hline PEG/SiO 2 -CPCMs & $70 \%$ & 42.4 & 54.6 & 65.2 & 82.1 & 39.4 & 34.2 & 26.3 & 75.9 \\
\hline
\end{tabular}

Note: The symbol Ton in the table is the melting (crystallizing) start temperature, Tp is the melting (crystallizing) peak temperature, Tend is the melting (crystallizing) end temperature, $\Delta \mathrm{Hm}$ is the melting enthalpy value, and $\Delta \mathrm{Hc}$ is the crystallizing enthalpy value.

The PEG-2000 phase change start temperature is about $40.4{ }^{\circ} \mathrm{C}$, the phase change end temperature is about $61.5^{\circ} \mathrm{C}$, and the peak value is about $52.5^{\circ} \mathrm{C}$; the $\mathrm{PEG} / \mathrm{SiO}_{2}-\mathrm{CPCM}$ phase change start temperature is about $42.4^{\circ} \mathrm{C}$, and the phase change end temperature is about $65.2{ }^{\circ} \mathrm{C}$, the peak value is about $54.6^{\circ} \mathrm{C}$. In the fields of architecture, roads and structures, the structure surface temperature caused by atmospheric temperature field could reach as high as above $50{ }^{\circ} \mathrm{C}$ [18-20]. Therefore, when applying $\mathrm{PEG} / \mathrm{SiO}_{2}-\mathrm{CPCM}$ to concrete structures, it can fully undergo phase change under high temperature conditions, thereby achieving the effects of energy storage and temperature regulation.

\subsection{Phase change cycle stability}

A certain amount of PEG/SiO 2 composite shape-stabilized phase change material particles were naturally deposited on a filter paper and placed in an oven at $200{ }^{\circ} \mathrm{C}$ for $2 \mathrm{~h}$, and then subject to $20-80^{\circ} \mathrm{C}$ thermal cycle for $10,20,50,100$, and 200 times. The phase change cycle stability of the $\mathrm{PEG} / \mathrm{SiO}_{2}$ 
composite shape-stabilized phase change material was investigated.

Table 5 shows the mass loss of $\mathrm{PEG} / \mathrm{SiO}_{2}-\mathrm{CPCM}$ after phase change treatment of different thermal cycles, the initial mass of the phase change material was $4 \mathrm{~g}$. The experimental results show that the mass of $\mathrm{PEG} / \mathrm{SiO}_{2}-\mathrm{CPCM}$ decreased with the increase of the number of cycles, and the mass loss rate tended to be stable. At the same time, after 200 times of thermal cycle treatment, the total mass loss rate of $\mathrm{PEG} / \mathrm{SiO}_{2}-$ CPCM was less than $1 \%$. Therefore, the use of silica sol as a carrier can achieve a good encapsulation shaping effect, and can maintain a high retention rate after multiple thermal cycles, ensuring that the phase change enthalpy and heat storage capacity do not change significantly.

Table 5. Mass of $\mathrm{PEG} / \mathrm{SiO}_{2}-\mathrm{CPCM}$ after multiple phase change cycles

\begin{tabular}{|c|c|c|c|c|c|c|}
\hline Cycle times & 0 & 10 & 20 & 50 & 100 & 200 \\
\hline Mass $(\mathrm{g})$ & 4.0000 & 3.9834 & 3.9725 & 3.9734 & 3.9646 & 3.9631 \\
\hline Loss rate $(\%)$ & 0.00 & 0.42 & 0.69 & 0.67 & 0.89 & 0.92 \\
\hline
\end{tabular}

\subsection{Mechanical properties of phase change concrete}

Figure 6 shows the compressive strength values of phasechange concrete with different mixing ratios after cured for 3 $\mathrm{d}, 7 \mathrm{~d}$ and $28 \mathrm{~d}$. The results show that the compressive strength of phase-change concrete decreased linearly with the increase of $\mathrm{PEG} / \mathrm{SiO}_{2}-\mathrm{CPCM}$ content, wherein the strength of PEG-V5 could reach the C50 grade requirement; while the strength of the $10 \% \sim 15 \%$ content group was greatly reduced, but since the concrete in the PEG group showed good working performance, the concrete's strength increment mode was similar to that of the common concrete.

From Figure 7, it can be seen that with the increase of age, the strength of phase change concrete with different $\mathrm{PEG} / \mathrm{SiO}_{2}-\mathrm{CPCM}$ content decreased continuously, and the change of strength of phase change concrete of PEG-V5 group was the most obvious, the decline range gradually decreased from the $27.62 \%$ of $3 \mathrm{~d}$ to only $4.96 \%$ of $28 \mathrm{~d}$; The strength of PEG-V10 group and PEG-V15 group phase change concrete decreased by more than $15 \%$, but for the phase change concrete with a $15 \%$ content, the compressive strength of $28 \mathrm{~d}$ still decreased by $57.07 \%$, reaching $22.4 \mathrm{MPa}$.

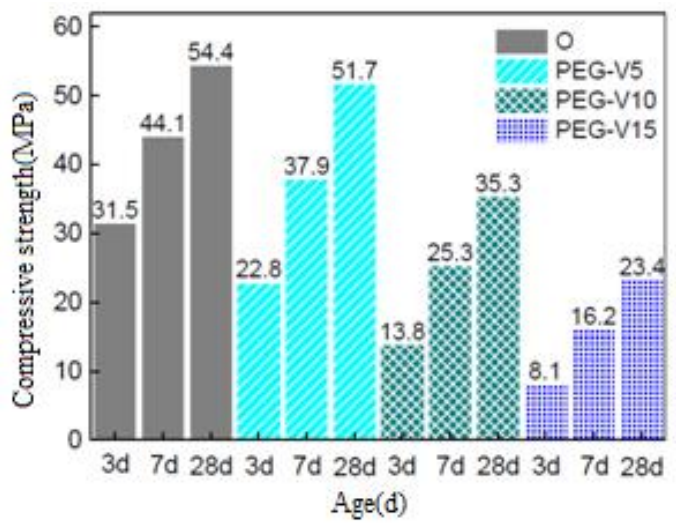

Figure 6. Phase change concrete compressive strength

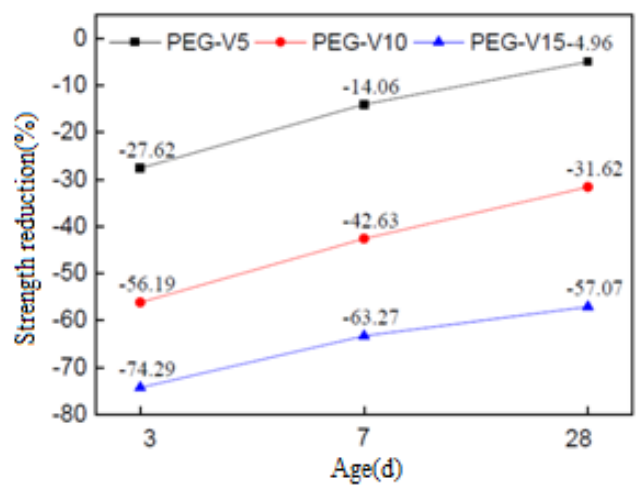

Figure 7. Strength change of phase change concrete

\subsection{Thermal conductivity of phase change concrete}

Table 6 lists the change law of thermal conductivity of common concrete and phase change concrete with a 5\% 15\% volume fraction content under the normal temperature and high temperature phase change conditions. The results show that at room temperature, the thermal conductivity of phase change concrete with $5 \%$ and $15 \%$ content is higher than that of common concrete, but the thermal conductivity of phase change concrete with $10 \%$ content is similar to that of common concrete. Through analysis, we believe that this is due to the decrease of the working performance of the concrete, the test pieces' pores and porosity increased, resulting in reduction in the thermal conductivity of the concrete plates; Under the high temperature conditions, the change law of the thermal conductivity is similar to that under the normal temperature conditions, but the thermal conductivity of the phase change concrete is reduced, through analysis, we believe that this is due to the PEG phase change in the concrete, a large amount of latent heat is absorbed, resulting in larger temperature differences between the cold plate and hot plate of the thermal conductivity instrument, so that the measured thermal conductivity becomes smaller.

Table 6. Thermal conductivity of phase change concrete $(\mathrm{W} / \mathrm{m} \cdot \mathrm{K})$

\begin{tabular}{|c|c|c|c|c|}
\hline No. & O & PEG -V5 & PEG -V10 & PEG -V15 \\
\hline Normal temperature test value & 1.5316 & 1.5491 & 1.5270 & 1.6070 \\
\hline High temperature test value & 1.3476 & 1.2417 & 1.1571 & 1.2439 \\
\hline
\end{tabular}

\section{CONCLUSION}

(1) $\mathrm{SiO}_{2}$ gel has a rich three-dimensional porous network structure and strong adsorption capacity, but the mass fraction of PEG in the composite shape-stabilized phase change material should be less than $90 \%$, and SEM and FT-RI test results indicate that the compatibility of $\mathrm{PEG}$ and $\mathrm{SiO}_{2}$ is good, and no chemical reaction occurs. After 200 thermal cycles, the 
mass loss rate is less than $1 \%$, so using silica sol as an inorganic porous carrier is feasible.

(2) DSC test results show that the start phase change temperature of $\mathrm{PEG} / \mathrm{SiO}_{2}-\mathrm{CPCM}$ is $42.4{ }^{\circ} \mathrm{C}$. During the heating process, the theoretical enthalpy of PEG/SiO ${ }_{2}-\mathrm{CPCM}$ is about $121.03 \mathrm{~J} / \mathrm{g}$, and the measured enthalpy is $82.1 \mathrm{~J} / \mathrm{g}$, the phase change enthalpy reduced by $38.93 \mathrm{~J} / \mathrm{g}$.

(3) With the increase of age, the strength of phase change concrete with different $\mathrm{PEG} / \mathrm{SiO}_{2}-\mathrm{CPCM}$ content decreases continuously, and the change of strength of phase change concrete of PEG-V5 group is the most obvious, the decline range gradually decreases from the $27.62 \%$ of $3 \mathrm{~d}$ to only $4.96 \%$ of $28 \mathrm{~d}$, but the strength meets the requirement of C50.

(4) Under the premise of ensuring good working performance of the concrete, the addition of a certain amount of $\mathrm{PEG} / \mathrm{SiO}_{2}-\mathrm{CPCM}$ can greatly enhance the thermal conductivity of the concrete, but its thermal conductivity is reduced when it undergoes phase change under high temperature conditions.

\section{ACKNOWLEDGMENT}

This work is supported by National Key R\&D Program of China (2017YFC0806007), The National Science Fund for Distinguished Young Scholars (51425801), Chongqing Technology Innovation and Application Demonstration Project (cstc2018jscx-mszdX0084).

\section{REFERENCES}

[1] Liu XF. (1985). Temperature distribution of concrete bridges. Journal of Railway Engineering Society (1): 107-111.

[2] Chen Z, Tang L. (2001). Temperature control of mass concrete in large bridges. Bridge Construction (1): 14-16.

[3] Shi W, Wang CT. (2015). Review of phase change materials research. Bulletin Bulletin 34(12): 3517-3522.

[4] Feng Z, Hu DX, Zhao L, Xue CZ. (2015). Review of research status of phase change materials in road engineering. Materials Review (S1): 144-147.

[5] Konuklu Y, Ostry M, Paksoy HO, Charvat P. (2015). Review on using microencapsulated phase change materials (PCM) in building applications. Energy and Buildings 106: 134-155. https://doi.org/10.1016/j.enbuild.2015.07.019

[6] Liu XL, Ke GJ, Tian B. (2015). Research status of phase change materials applied in mass concrete. New Building Materials (5): 81-85. http://dx.chinadoi.cn/10.3969/j.issn.1001702X.2015.05.024

[7] Liu Z, Yu ZJ, Yang T, Qin D, Li SS, Zhang GQ. (2018). A review on macro-encapsulated phase change material for building envelope applications. Building and Environment 144: 281-294.
[8] Li YT, Yan H, Wang HT, Yu RS. (2016). Structure and properties of expanded graphite-based composite phase change materials. Chinese Journal of Materials Research (7): 545-552

[9] Zhao SX, Yan H, Li YT, Dai J. (2017). Properties of paraffin/expanded perlite composite phase change materials. New Chemical Materials (9): 89-91.

[10] Kahwaji S, White MA. (2018). Prediction of the properties of eutectic fatty acid phase change materials. Thermochimica Acta 660: 94-100. http://dx.doi.org/10.1016/j.tca.2017.12.024

[11] Alkan C, Günther E, Hiebler S, Ensari OF, Kahraman D. (2012). Polyurethanes as solid-solid phase change materials for thermal energy storage. Solar Energy 86(6): 1761-1769. https://doi.org/10.1016/j.solener.2012.03.012

[12] Fang YT, Kang HY, Wang WL, Liu H, Gao XN. (2010). Study on polyethylene glycol/epoxy resin composite as a form-stable phase change material. Energy Conversion and Management. Energy Conversion and Management 51 https://doi.org/10.1016/j.enconman.2010.06.012 2757-2761

[13] Feng LL, Zhao W, Zheng J, Frisco S, Song P, Li XG. (2011). The shape-stabilized phase change materials composed of polyethylene glycol and various mesoporous matrices (AC, SBA-15 and MCM-41). Solar Energy Materials and Solar Cells 95(12): 3550-3556. http://dx.doi.org/10.1016/j.solmat.2011.08.020

[14] Yang HZ, Feng LL, Wang CY, Zhao W, Li XG. (2012). Confinement effect of $\mathrm{SiO}_{2}$ framework on phase change of $\mathrm{PEG}$ in shape-stabilized $\mathrm{PEG} / \mathrm{SiO}_{2}$ composites. European Polymer Journal 48(4): 803-810. http://dx.doi.org/10.1016/j.eurpolymj.2012.01.016

[15] Suchithra PS, Vazhayal L, Mohamed AP, Ananthakumar S. (2012). Mesoporous organic-inorganic hybrid aerogels through ultrasonic assisted sol-gel intercalation of Silica-PEG in bentonite for effective removal of dyes, volatile organic pollutants and petroleum products from aqueous solution. Chemical Engineering Journal 200202: 589-600. https://doi.org/10.1016/j.cej.2012.06.083

[16] He LH. (2016). Preparation and cooling mechanism of composite phase change heat storage asphalt pavement materials. Chongqing Jiaotong University.

[17] Huang JF. (2005). Principle and technology of Sol-Gel. Chemical Industry Press.

[18] Han ZD. (2001). Study on temperature field of road structure. Chang'an University.

[19] Jin WL, Ye JZ, Yan JY, Xu QB, Pan JL. (2002). Temperature field of concrete hollow small block building. Industrial Construction (10): 28-30. http://dx.chinadoi.cn/10.3321/j.issn:10008993.2002.10.010

[20] Feng WT. (2018). Temperature effect analysis of stiff skeleton concrete arch bridge under solar radiation. Southwest University of Science and Technology. 